\title{
KEPEMIMPINAN KEPALA SEKOLAH DALAM PENGUATAN PERAN MULTI-STAKEHOLDERS FORUM (Masalah dan Strategi Solutif Peningkatan Mutu SD - SMP Satu Atap di Daerah Terpencil)
}

\author{
Juharyanto \\ Sultoni \\ Imron Arifin \\ Ahmad Nurabadi \\ Jurusan Administrasi Pendidikan, Fakultas Ilmu Pendidikan \\ Universitas Negeri Malang \\ e-mail: juharyanto.fip@um.ac.id
}

Artikel diterima: 15 April 2019; disetujui: 31 Mei 2019

\begin{abstract}
The study aims to describe the problem and find effective leadership strategies that can be done by principals in Elementary School - Junior High School One Roof (SATAP) in remote areas. Qualitative research with a multi-site approach. The data was obtained through the principal, the head of the LPIKIPI representative (Training Institute and Indonesian Educational Innovation Consultant), and tested the credibility and validity in triangulation through the Forum Group Discussion (FGD) and expert testing. The results obtained include: 1) the problems faced by one-roof principals in remote areas are closely related to aspects of cultural, social, economic, demographic, and geographic aspects, as well as historically; 2) effective school leadership solution strategies emphasizing spiritual, personal, and social aspects.
\end{abstract}

Keywords: leadership of principals, multi-stakeholders forums, improvement of school quality, remote areas.

\begin{abstract}
Abstrak: Penelitian bertujuan untuk mendeskripsikan permasalahan dan menemukan strategi kepemimpinan efektif yang dapat dilakukan kepala sekolah pada SD - SMP Satu Atap (SATAP) di daerah terpencil. Penelitian kualitatif dengan pendekatan multi-situs. Data diperoleh melalui kepala sekolah, ketua perwakilan LPIKIPI (Lembaga Pelatihan dan Konsultan Inovasi Pendidikan Indonesia), dan diuji kredibilitas dan validitasnya secara triangulasi melalui Forum Grup Discussion (FGD) dan uji ahli. Hasil yang diperoleh antara lain: 1) permasalahan yang dihadapi kepala sekolah satu atap daerah terpencil sangat terkait dengan aspek-aspek aspek budaya, sosial, ekonomi, demografi, dan geografi, serta historis; 2) strategi solutif kepemimpinan efektif sekolah menekankan pada aspek spiritual, personal, dan sosial.
\end{abstract}

Kata kunci: kepemimpinan kepala sekolah, multi-stakeholders forum, peningkatan mutu sekolah, daerah terpencil.

Keberadaan kepala sekolah menjadi penentu yang sangat utama terhadap mutu pendidikan (Gibson, 2014; Pan, Nyeu, \& Chen, 2015; Urick, 2016). Mutu pendidikan ditandai luaran yang berkemampuan untuk mengoptimalkan potensinya dalam menunjang kebutuhan kehidupan (I Made Artha Wibawa, Eka Afnan Troena, Armanu, NoermijatiLumpkin, 2014; Tchibozo, 2013). Implementasi tugas kepemimpinan kepala sekolah dalam meningkatkan mutu sekolah, tidak mudah. 
Sekolah-sekolah yang berlokasi di daerah terpencil dengan karakter: medan yang tidak bersahabat, secara umum kondisi ekonomi sangat rendah, rendahnya kesadaran pendidikan masyarakat, sarana dan pra-sarana sekolah tidak memadai, kuantitas dan kualitas guru kurang memadai, dominasi status guru yang masih non-PNS, dan faktor kebijakan pemerintah yang cenderung berubah sewaktu-waktu, justru semakin menyulitkan kepala sekolah (Hyson, 2013; Juharyanto, 2017; Piter Joko Nugroho, 2014). Tugas kepala untuk mempertahankan sekolah dalam kondisi yang sangat terbatas, atau bahkan mengembangkan sekolah tersebut sesuai dengan standar mutu nasional bisa jadi merupakan mimpi buruk bagi mereka. Hal tersebut menjadi salah satu alasan para guru menghindar untuk diangkat sebagai kepala sekolah. Akibatnya, atas dasar persoalan manajerial saja akhirnya kepala sekolah harus diangkat untuk memimpin sekolah. Penetapan kepala sekolah mempertaruhkan dua sisi pilihan kepentingan yang kontradiktif, yakni kepala sekolah harus tetap ada atau adanya kepala sekolah namun tidak bermutu (Ayene Tamrat Atsebeha, 2016; Sigrr' ður Margre 't Sigurðardo ' ttir, 2016).

Apapun sisi pilihannya, kepala sekolah wajib menjalankan tugas kepemimpinannya semaksimal mungkin. Faktanya, beberapa di antara kepala sekolah berhasil melakukan lompatan mutu sekolah dengan sangat baik, terutama kepala sekolah yang sadar bahwa peningkatan mutu sekolah bukan meurupakan tugas seorang diri, dan masih terdapat stakeholders yang peduli untuk bersamasama meningkatkan mutu sekolah dengan harapan yang sama, yakni untuk melahirkan generasi penerus mereka di masa depan yang lebih baik. Keberhasilan kepala sekolah, ditentukan oleh tingginya spirit kepemimpinan. Selain spirit, mereka meyakini bahwa dapat berperan ganda secara antagonis, yakni pengembang mutu sekolah atau penghancur keberadaan sekolah itu sendiri (Ayene Tamrat Atsebeha, 2016). Kesadaran tentang peran tersebut, mampu mendorong kepala sekolah untuk memformulasikan diri kepala sekolah dalam melakukan berbagai kreasi dan inovasi pemikiran dan tindakan konsisten dalam memajukan sekolahsekolah, termasuk sekolah terpencil, bahkan SD SMP SATAP.

Sekolah Satu Atap adalah sekolah dasar dan sekolah menengah pertama yang diselenggarakan secara terpadu di satu gedung sekolah dasar
(Wulandari2, 2018; Yuliastuti, Syukri, \& Martono, 2016)maka kepemimpinan kepala Sekolah dalam Menyelenggarakan pendidikan sekolah satu atap di Kecamatan Kuala Mandor Kabupaten Kubu Raya dengan Mengambil Kasus pada SD N 21 dan SMP N 5 Kuala Mandor B dapat di tarik kesimpulan : 1.. Pendirian SD - SMP SATAP, disamping didasari oleh kebijakan efisiensi pendidikan, juga didorong oleh semakin tidak terjangkaunya sekolah-sekolah menengah oleh lulusan sekolah dasar, baik karena alasan geografis, ekonomis, bahkan budaya (Tveit, Cameron, \& Kovač, 2014). Karena itu, keberadaan SD - SMP SATAP memiliki peran sangat strategis dalam implementasi kebijakan tentang pendidikan dasar sembilan tahun (akses) sekaligus peningkatan mutu sumber daya manusia.

Beragam persoalan yang dihadapi sekolah satu atap, antara lain: 1) tidak dimilikinya guru khusus oleh sebagian besar SD - SMP SATAP; 2) Sebagian besar guru SD - SMP SATAP merupakan guru pada Sekolah Dasar setempat, yang belum memiliki kelayakan kinerja setara SMP; 3) Kepala Sekolah harus memerankan dua aktivitas manajemen dan kepemimpinan berbeda karakteristik; 4) rendahnya dukungan moral dan finansial wali murid; 5) rendahnya kesadaran belajar; dan lain-lain (ISTININGSIH, 2013; Juharyanto, 2017; Wijayanti, 2011). Oleh karena itu, menjadi kepala SATAP di daerah terpencil tidak mudah.

Daerah terpencil merupakan suatu komunitas masyarakat yang terisolir dari hampir semua perubahan menuju kemajuan (Findlay, 2003). Sekalipun piranti teknologi sudah mulai merambah generasi muda, kebanyakan penggunaannya masih bersifat euforia dan lebih cenderung pada teknologi hiburan, games, dan short message, bukan pada aspek kebutuhan pengembangan diri berbasis teknologi masa depan (Zakub, Widodo, \& Setiawan, 2018). Keberadaan teknologi tersebut bahkan justru menggiring mereka ke dalam pemikiran parsial tentang makna hidup yang membentuk mindset tentang benar-salah, positif-negatif, kemajuankemerosotan, kebutuhan hidup-gaya hidup, dan lain-lain. Latar pendidikan yang mayoritas masih rendah berkorelasi signifikan terhadap rendahnya kedewasaan memikirkan dampak teknologi secara positif, terutama pada anak muda pedesaan saat ini (Arnold, Newman, Gaddy, \& Dean, 2005; Findlay, 2003; Schrag, 2016). Dalam kondisi demikian, peran sekolah menjadi rumit. Dalam kerumitan 
tersebut, peran kepala sekolah dituntut konsisten sebagai agen peubah bagi kehidupan masyarakat melalui sekolah binaannya (Wahyono, 2011).

Walaupun demikian, komitmen mempertahankan kultur dan relasi sosial yang masih melekat, merupakan aspek potensial untuk dimanfaatkan kepala sekolah dalam melakukan perubahan. Budaya "buphak-bhabuk-ghuru-ratoh" pada masyarakat suku Madura (Hefni, 2007), atau kultur "unggah-ungguh" pada masyarakat suku Jawa (Trianton, 2015), masih diyakini sebagai pitutur luhur dan sangat layak dipegang teguh serta dikembangkan oleh mereka (Zakub et al., 2018). Budaya demikian, merupakan "pintu utama" yang dapat dimasuki kepala sekolah untuk memasuki ruang-ruang budaya tersebut, menguatkan kualitas keberterimaan kepala sekolah melalui penguatan peran stakeholders masyarakat agar mendukung ketercapaian program-program sekolah secara bersama-sama.

Menempatkan "masyarakat" ke dalam program sekolah melalui strategi berbasis kultur tersebut, merupakan peluang besar bagi kepala sekolah untuk meraih dukungan masyarakat dalam memajukan sekolah (Bowe, Ball, Gold, Ball, \& Gold, 2017; Faegerlind \& Saha, 2016). Aktivitas tersebut tidak mudah dilakukan dan sulit berhasil, kecuali jika kepala sekolah memiliki kemampuan untuk mendekati tokoh-tokoh utama masyarakat. Menggunakan pendekatan-pendekatan tertentu melalui peran para tokoh tersebut justru akan menguatkan keberadaan kepala sekolah dalam memperjuangkan capaian program sekolah itu sendiri (Agbaria, 2015; Banks, 1997; Tilaar, 1998) this article grapples with the educational activism of Arab civil society in Israel. Specifically, it presents a case study of a recent initiative to establish an independent Arab Pedagogical Council (APC. Tokoh-tokoh masyarakat tersebut merupakan representasi berbagai status dan profesi (multistakeholders), yang dengan karakteristiknya masingmasing, peran-peran tersebut dapat dimaksimalkan untuk mengangkat beragam keunggulan masyarakat bagi kemajuan sekolah, terutama di daerah terpencil. Eksistensi multi-stakeholders harus menjadi pusat perhatian kepala sekolah. Seluruh anggota masyarakat pasti ingin mewujudkan citacita terbaik anak-anaknya sebagai pemegang estafet kehidupan yang lebih baik di masa depan (Schneider \& Buckley, 2002). Memasuki dunia masyarakat melalui strategi terpilih, merupakan potensi besar yang penting untuk ditempuh kepala sekolah guna mewujudkan mutu layanan di sekolah semaksimal mungkin.

\section{METODE}

Penelitian ini bertujuan untuk mendeskripsikan permasalahan dan menemukan strategi kepemimpinan kepala sekolah solutif dalam menguatkan peran multistakeholders forum untuk meningkatkan mutu sekolah di SD - SMP SATAP daerah terpencil. Ide awal penelitian ini berasal dari beragam informasi tentang pengelolaan sekolah satu atap di daerah terpencil yang dikembangkan oleh kepala sekolah melalui beragam strategi melalui intervensi pemerintah daerah dan mediasi LPIKIPI (Lembaga Pelatihan dan Konsultan Inovasi Pendidikan Indonesia). Informasi pengelolaan SD - SMP SATAP yang sangat penting terbagi ke dalam tiga kategori, antara lain: 1) pengelolaan SD - SMP SATAP yang gagal; 2) pengelolaan SD - SMP SATAP yang berhasil melalui pengelolaan murni oleh satu orang kepala sekolah dan tim internal sekolah; 3) pengelolaan SD - SMP SATAP yang berhasil dilakukan oleh dua orang kepala sekolah (SD dan SMP); 4) pengelolaan SD - SMP SATAP yang berhasil dengan sangat baik dan memiliki potensi keberlanjutan karena didukung oleh peran dan fungsi stakeholders. Keempat kategori tersebut sejak awal melakukan pendekatan yang sama, yakni melibatkan peran dan fungsi stakeholders sebagaimana rekomendasi LPIKIPI sebagai bentuk mediasi pengembangan mutu SD - SMP SATAP.

Kategori keempat memiliki daya tarik untuk ditelaah secara mendalam secara naturalistis dan dikaji secara reflektif, dengan pertimbangan utama keberhasilan kepala sekolah dalam mendorong dan memaksimalkan keterlibatan peran dan fungsi stakeholders, yang sejak awal meurupakan sesuatu yang sangat sulit dilakukan. Namun melalui eksperimentasi beragam strategi, akhirnya kepala sekolah berhasil mewujudkannya.

Penelitian ini diangkat dari fenomena nyata melalui beragam permasalahan dan pertimbangan tersebut ditelusuri secara naturalistis, melalui wawancara mendalam tidak terstruktur, observasi, dan telaah dokumen, termasuk notulen MSF. Hasilhasil temuan tersebut kemudian diverifikasi secara reflektif melalui FGD dalam berbagai kegiatan yang relevan, misalnya dalam forum MSF SD - 
SMP SATAP, forum Diklat Penguatan Kompetensi Manajerial Kepala Sekolah se Kota Malang, dan forum lainnya.

Secara keseluruhan jumlah responden sebanyak 237 orang, dengan sebaran 21 orang untuk kepentingan data primer, dan 216 orang untuk kepentingan data sekunder. Untuk keperluan validitas data, digunakanlah analisa reduksi, presentasi, verifikasi, dan penyimpulan. Di samping itu, uji validitas data juga dilakukan pembuktian kredibilitas melalui quasi participant observation, member check, dan uji antar kolega. Kemudian diuji dependabilitasnya melalui proses audit data di lapangan, serta konfirmabilitasnya melalui melihat hubungan antara data yang diperoleh, informasi yang diterima, dan interpretasi yang ditemukan.

\section{HASIL}

\section{Permasalahan SD - SMP SATAP Daerah Terpencil}

Sekolah satu atap didirikan sebagai solusi terhadap rendahnya akses tuntas wajib belajar pendidikan dasar 9 tahun, terutama di daerahdaerah terpencil. Terdapat beberapa masalah yang dihadapi oleh SD - SMP SATAP. Masalah tersebut berhubungan dengan aspek budaya, sosial, ekonomi, demografi, dan geografi, serta historis.

Aspek budaya

SD - SMP SATAP berhadapan dengan beberapa masalah berikut, antara lain: 1) stigma tentang sekolah umum tidak lebih penting dari pada sekolah-sekolah berbasis keagamaan, semisal lembaga pendidikan Diniyah, surau, pondok pesantren, atau penyelenggara pendidikan keagamaan lainnya. 2) Masih terjadinya pernikahan usia anak, khususnya bagi anak-anak perempuan. Para orang tua mengalami kebingungan, bahkan seolah menanggung rasa malu ketika anak-anak perempuan mereka tidak ada yang meminangnya di usia-usia 12 - 15 tahun. Mereka menganggap bahwa anaknya tidak laku dan cenderung kadaluwarsa. Dalam keadaan seperti itu, para orang tua akan memindahkan anak-anak mereka ke pondok pesantren, justru di saat masih duduk di kelas lima atau enam. Upaya tersebut dianggap sebagai cara efektif untuk menaikkan status sosialnya dan diyakini berdampak pada naiknya nilai tawar putrinya di mata masyarakat. 3) sekolah umum masih dianggap sebagai lembaga yang menghalangi transformasi nilai-nilai dan norma-norma yang berlaku di tempat tersebut. Pendidikan umum distigmakan sebagai lembaga pendidikan tertentu yang cenderung membekali anak-anak dengan nilainilai kebebasan berekspresi, bebas berpendapat, dan kemampuan kritis terhadap tatanan yang sudah dianggap mapan. 4) masyarakat terpencil memiliki budaya kaget yang tinggi. Teknologi yang sudah berada dalam genggaman tidak sepadan dengan kualitas pendidikan anak-anak pedesaan, sehingga ragam informasi dan nilai-nilai budaya luar dapat dengan bebas dan masif memengaruhi cara berpikir dan bertindak anak-anak tersebut. Keadaan tersebut dianggap sangat membahayakan kelangsungan budaya setempat. Karena itu, pendidikan keagamaan menjadi pilihan utama dan pertama yang dianggap paling efektif.

Aspek sosial

Pendidikan umum distigmakan sebagai lembaga pendidikan yang menanamkan nilai-nilai individualistis, kompetitif, dan sarkastis. Nilainilai tersebut sangat bertolak belakang dengan tradisi yang berkembang dan terus dikembangkan mereka hingga saat ini. Masyarakat desa sangat yakin bahwa tradisi yang dikembangkan merupakan tradisi yang sudah mapan dan matang yang melahirkan kekompakan, persahabatan, perasaan saling membutuhkan, kedekatan individual dan sosial, tolong menolong tanpa pamrih, prinsip berkembang bersama, saling asah-asih-asuh, dan lain-lain. Pendidikan umum dianggap sebagai ancaman terhadap kemapanan tersebut.

\section{Aspek ekonomis}

Kehadiran sekolah dengan waktu belajar setengah hari dianggap menutup peluang memeroleh tambahan penghasilan. Bagi mereka penghasilan jauh lebih penting daripada pendidikan. Mayoritas anak-anak usia sekolah masih bekerja di ladang dan perkebunan untuk bekerja dan mendapatkan penghasilan, terutama pada musim tanam dan panen. Musim-musim tersebut merupakan peluang besar dan sangat menguntungkan untuk mendapatkan penghasilan yang tinggi. Karena itu, pendidikan, terutama pendidikan umum dianggap merupakan ancaman serius bagi pertumbuhan ekonomi keluarga masyarakat setempat.

\section{Aspek demografis}

Mayoritas penduduk terutama para orang tua peserta didik di daerah-daerah terpencil mencari 
kerja di tempat lain bahkan di luar pulau yang lebih menjanjikan. Anak-anak mereka dipercayakan kepada kakek dan nenek mereka. Secara demografis, penduduk di daerah terpencil tidak saja kekurangan penduduk karena tradisi bekerja di luar pulau, melainkan motivasi untuk memeroleh pendidikan sangat rendah karena tidak adanya asuhan langsung dari orang tua mereka, yang sebenarnya merupakan kelompok usia tertentu yang memiliki kualitas pengetahuan dan keterampilan lebih maju daripada kakek dan nenek mereka.

\section{Aspek Geografis}

Lokasi dengan latar daerah pegunungan dan perbukitan disertai dengan infrastruktur yang tidak memadai serta jarak akses antar komunitas yang berjauhan menjadi penghalang memeroleh pendidikan. Keadaan tersebut juga dilatari oleh lokasi pemukiman penduduk yang berjauhan dengan tempat penyelenggaraan pendidikan tersebut. Hal tersebut akan menjadi lebih sulit pada musimmusim hujan, di mana aktivitas sekolah sangat bergantung pada keadaan cuaca dan aktivitas hujan yang memengaruhi kondisi geografis semakin tidak memungkinkan dilakukannya perjalanan menuju sekolah dengan aman dan nyaman.

\section{Aspek historis kepemimpinan terdahulu}

Di beberapa daerah terpencil tertentu, sering terjadi leadership test-case, di mana masyarakat tidak langsung percaya terhadap kehadiran kepala sekolah baru. Peran-peran yang dijalankan kepala sekolah terdahulu, perilaku dan kedekatannya terhadap masyarakat serta kegigihan dan keberhasilannya memandu pendidikan dan masyarakat secara keseluruhan memberi andil terhadap tingkat keberterimaan kepala sekolah baru sebagai pemimpin berikutnya. Bahkan, masyarakat tertentu telah memiliki standar performansi sebagai prasyarat yang harus melekat dan dilakukan oleh kepala sekolah agar diterima dan didukung oleh masyarakat setempat.

\section{Strategi Kepemimpinan Solutif Kepala Sekolah Sebagai Penentu Keberhasilan Penguatan Peran MSF bagi Peningkatan Mutu SD - SMP SATAP Daerah Terpencil}

Keberhasilan kepala SD - SMP SATAP dalam menguatkan peran MSF sehingga memberikan dukungan yang tinggi terhadap program sekolah ditentukan oleh karakter-karakter spesifik. Internalisasi beragam karakter tersebut ke dalam tindak laku keseharian kepala sekolah meurupakan strategi kepemimpinan yang memberikan dukungan tinggi terhadap keberhasilan kepala sekolah. Karakteristik tersebut bahkan seolah merupakan standar yang ditetapkan oleh masyarakat setempat. Strategi solutif tersebut bertumpu pada tiga karakter kepemimpinan utama, antara lain: 1) spiritual; 2) personal; dan 3) sosial.

\section{Strategi berbasis karakter spiritual}

Kepala sekolah menyadari bahwa tradisi dan spiritualitas masyarakat menjadi hal yang sangat penting di didukung dan dikuatkan melalui internalisasi nilai-nilai tersebut ke dalam sikap dan perilaku keseharian kepala sekolah. Masyarakat daerah terpencil, pada umunya terdiri dari anggotaanggota yang memiliki kualitas spiritual yang cukup memadai, setidaknya dalam implementasi nilai budaya spiritual. Performansi nilai-nilai budaya spiritualitas yang dipatrikan kepala sekolah dalam berinteraksi dengan seluruh anggota masyarakat, memberikan dampak yang signifikan terhadap tingginya dukungan masyarakat kepada kepala sekolah. Salah satu nilai penting adalah dimilikinya keyakinan tinggi bahwa pasti terdapat jalan keluar dari setiap masalah. Apapun masalahnya, selama orientasi pemecahan masalahnya dinilai baik dan positif, Tuhan pasti akan memberikan jalan keluar terbaik. Nilai-nilai tersebut dipegang dengan sangat erat oleh masyarakat. Keyakinan tersebut ditunjukkan dengan tingginya frekuensi aktivitas peribadatan yang dilakukan masyarakat, baik dalam konteks ritualitas peribadatan maupun dalam ritualitas kemasyarakatan. Keterlibatan kepala sekolah dalam aspek spiritual bersama masyarakat, akan membentuk keyakinan masyarakat terhadap kesamaan identitas spiritual, dan menciptakan dukungan tinggi dari masyarakat tersebut.

\section{Strategi berbasis karakter personal}

Kepemilikan nilai-nilai karakter personal merupakan syarat utama bagi keberhasilan implementasi kepemimpinan kepala sekolah dan berdampakpadatimbul,tumbuh, dan berkembangnya atensi dan kepercayaan masyarakat terhadapnya. Karakter personal mengarah pada kepemilikan visi jelas, tampil dengan spirit tinggi, andhab asor (low profile), kemauan keras untuk belajar tanpa henti, bersikap terbuka terhadap masukan, gigih dan tidak mudah menyerah, kreatif, sabar, santun, good looking atau tampil menarik. Kepala sekolah yang efektif, tidak saja harus didukung oleh karakter 
spiritual, melainkan juga karakter personal, sebagai bentuk riil terintegrasinya nilai-nilai spiritual ke dalam pribadi-pribadi kepala sekolah. Masyarakat menilai bahwa karakter spiritual memang sangat penting, namun wujud spiritualitas ke dalam personalitas diri kepala sekolah merupakan aspek yang lebih penting.

\section{Strategi berbasis karakter sosial}

Bagaimanapun, kepemimpinan tidak pernah dapatdipisahkandarikonteksrelasisosial.Karenanya, kepala sekolah efektif sangat dipengaruhi juga oleh tingginya kepemilikan dan perwujudan nilainilai karakter sosial. Karakter sosial ditunjukkan dengan ciri-ciri melibatkan diri ke dalam beragam aktivitas kemasyarakatan, mempunyai kesadaran tinggi bahwa sekolah pada hakikatnya merupakan sistem pendidikan dan merupakan bagian penting dari sistem kemasyarakatan secara umum, mempunyai keyakinan bahwa dia tidak sendirian dalam menjalankan kebijakan sekolah, memiliki ketajaman melihat konteks, dan mudah bergaul.

\section{Penguatan Peran MSF Dalam Peningkatan Mutu SD - SMP SATAP}

Dalam upaya penguatan peran MSF bagi peningkatan mutu sekolah, pertama-tama yang dilakukan kepala sekolah adalah mengidentifikasi tokoh kunci utama (TKU). TKU tersebut merupakan orang yang memiliki pengaruh kuat di mana segala petuturannya senantiasa ditunggutunggu, didengar, dan dipatuhi serta dilaksanakan. Selanjutnya dilakukan komunikasi intensif melalui jalinan silaturahmi terus menerus. Topik-topik yang dibahas dalam setiap pertemuan tersebut antara lain: karakter masyarakat setempat, harapan masyarakat terhadap sekolah, peran timbal balik yang dapat dimainkan oleh pihak sekolah dan masyarakat, identifikasi tokoh-tokoh penting lainnya, menyusun rencana dan strategi lebih membangun interaksi dengan tokoh-tokoh penting lain, kemungkinan berbagi peran dengan tokoh-tokoh penting lain. Luaran yang diharapkan dalam setiap pertemuan dengan TKU tersebut adalah kesepahaman dan komitmen mendukung ketercapaian visi SD - SMP SATAP sebagai bentuk ringkas dari visi masyarakat secara keseluruhan.

Kesepahaman dan komitmen yang telah terbentuk, dilanjutkan dengan melakukan silaturahmi lebih luas dan komprehensif melalui strategi berbasis karakter spiritual, personal, dan sosial yang dilakukan secara informal berbasis budaya lokal setempat bersama-sama oleh kepala sekolah dan TKU tersebut terhadap tokoh kunci teridentifikasi lainnya. Tokoh-tokoh tersebut antara lain: kepala desa, ketua karang taruna, badan perwakilan desa (BPD), Posyandu, Ponkesdes, Kepala Perkebunan, Polsek, Koramil, ulama, Kepala Kecamatan dan unsur-unsur terkait, serta para kepala kampung desa setempat. Silaturahmi tersebut dilakukan secara personal, individual, bersifat ngangsu kaweruh, membangun empati dan dukungan serta berbagi peran untuk melaksanakan tugas berbagi topik dan peran berikutnya. Setelah kesepahaman dan komitmen terjalin, maka dilanjutkan untuk mengatur jadwal pertemuan bersama untuk berbagi informasi, diskusi tentang pemenuhan harapan masyarakat dan SD - SMP SATAP, serta berbagi peran dalam menyelesaikan setiap masalah SD - SMP SATAP sesuai dengan bidang atau kluster masing-masing dalam forum MSF.

\section{PEMBAHASAN}

Dari berbagai deskripsi tersebut dapat dijelaskan bahwa pada dasarnya mengelola dan mengembangkan SD - SMP SATAP di daerah terpencil memang sangat sulit. Tidak semua kepala sekolah mampu mengelola dan mengembangkan sekolah semacam itu (Epstein, 2018). Di beberapa negara seperti Australia, Jepang, India, Afrika, dan negara-negara kawasan dunia lainnya memiliki masalah dan tantangan yang relatif sama dalam pengembangan sekolah-sekolah di daerah terpencil, antara lain masalah budaya, sosial, ekonomi, geografis, dan demografis, yang secara keseluruhan berdampak pada sangat lambannya capaian mutu sekolah (Areas, 2013; Griffiths, 1968; Sahni, 2015; Sealander, Eigenberger, Peterson, Shellady, \& Prater, 2001; Starr \& White, 2008). Permasalahan tersebut tentu sudah didekati dengan berbagai langkah strategis untuk ditanggulangi dari waktu ke waktu. Khusus kasus, masalah-masalah tersebut juga didukung oleh sikap memandang rendah terhadap kepala sekolah baru yang disebabkan oleh kegagalan kepemimpinan kepala sekolah sebelumnya. Masih banyak masyarakat di daerah terpencil yang menggeneralisasi suatu kegagalan terhadap kemungkinan kegagalan berikutnya. Masalah tersebut justru memberikan andil terhadap kegagalan kepala sekolah selanjutnya. Di samping itu, masalah kebersihan dan kesehatan lingkungan 
merupakan masalah khusus yang lain yang dihadapi sekolah-sekolah pada daerah-daerah terpencil, sebagai mana juga terjadi di Zimbabwe (Mutale, 2015).

Permasalahan tersebut sering kali menyita waktu, pikiran, dan tenaga kepala sekolah dan para guru serta staf yang lebih banyak daripada perhatian mereka terhadap peningkatan dan pengembangan mutu sekolah. Dalam keadaan demikian, kegagalan kepemimpinan yang dialami kepala sekolah sering memeroleh pemakluman dari berbagai pihak, walaupun ada beberapa kepala sekolah yang berhasil keluar dari masalah tersebut dengan cepat, dan membaliknya menjadi suatu tantangan dan peluang keberhasilan dalam meningkatkan dan mengembangkan mutu sekolah bahkan masyarakat sekolah secara keseluruhan (Postiglione, Jiao, \& Xiaoliang, 2012). Kegagalan kepemimpinan kepala sekolah kadang tidak disebabkan oleh banyaknya permasalahan yang dihadapi, melainkan ketidakmampuan mereka menghadapi permasalahan tersebut sebagai suatu fakta, yang sebenarnya dapat dijadikan peluang baik untuk mengelola masalah tersebut secara tepat, terutama bagi peningkatan dan pengembangan mutu sekolah.

Menjadi kepala sekolah tidak mudah. Mereka merupakan orang-orang terpilih karena telah memenuhi syarat sebagai kepala sekolah. Untuk dapat diangkat sebagai kepala sekolah, mereka harus memiliki setidaknya 5 (lima) kompetensi antara lain: manajerial, kewirausahaan, supervisi, kepribadian, dan sosial (Kementerian Pendidikan Nasional, 2007). Dalam beberapa penelitian diketahui bahwa salah satu persyaratan yang paling utama harus dipenuhi oleh kepala sekolah adalah kompetensi kepribadian (Ibukun, Oyewole, \& Abe, 2011), yang melekat pada diri mereka sebagai identitas profesional dan emosional dalam menjalankan kepemimpinannya (Crow, Day, \& Møller, 2017).

Temuan penelitian Ibukun, dkk. dan Crow, dkk. tersebut, relatif sama dengan kasus, khususnya di daerah terpencil, dimana kompetensi kepribadian merupakan prasyarat utama yang harus dipenuhi sesuai dengan karakteristik masyarakat di tempat tersebut. Memenuhi standar kompetensi kepribadian dapat dianalogkan sebagai upaya memenuhi standar nilai yang ditetapkan dan diharapkan masyarakat. Kualitas kepribadian yang tinggi dapat merupakan salah satu faktor penting terhadap terbangunnya kepercayaan orang lain (Grankvist \& Kajonius,
2015). Jika standar tersebut telah diraih dan dilaksanakan dengan sungguh-sungguh, maka masyarakat akan menerima dan mendukung semua kebijakan yang diprogramkan oleh kepala sekolah (Schrag, 2016). Kepribadian, merupakan aspek kunci bagi menguatnya kualitas keberterimaan dan dukungan masyarakat terhadap sekolah.

Sebagaimana dijelaskan di muka bahwa pelibatan stakeholders ke dalam forum-forum tertentu (MSF) yang diselenggarakan sekolah memberikan andil besar terhadap efektivitas dan efisiensi capaian program sekolah (Tulder, 2011). Aktivitas diskusi dan negosiasi para pemangku kepentingan majemuk tersebut sangat efektif dalam menentukan arah kebijakan organisasi secara sistemis dan kompleks, sebagaimana kompleksitas sumber-sumber daya yang tergabung dalam kelompok tersebut. Peran penting keterlibatan MSF yang demikian tinggi bagi keberhasilan sekolah perlu didukung dan dikuatkan dalam bentuk forumforum selanjutnya secara terprogram dengan baik (Tulder, 2011). Bagaimanapun, kepala sekolah bukan satu-satunya orang yang bertanggungjawab terhadap masa depan sekolah. perlu dukungan berbagai pihak agar cita-cita sekolah dapat diraih secara maksimal. Dengan demikian, melibatkan peran MSF bukan sekedar pelibatan orang-orang tertentu tanpa seleksi dan rekomendasi. Seleksi dan rekomendasi perlu dilakukan atas dasar masukan dan saran para tokoh kunci utama (TKU). Melibatkan TKU berarti memberikan kepercayaan kepada orang-orang tertentu yang terpercaya untuk menyeleksi dan merekomendasi tokoh-tokoh penting lainnya yang memiliki tingkat kelayakan tertentu sesuai dengan harapan kepala sekolah sebagaimana dikomunikasikan sebelumnya. Melibatkan stakeholders juga dilakukan untuk memberikan pembekalan atau informasi terkait dengan pengembangan sekolah agar partisipasi yang diberikan tetap relevan dengan kepentingan sekolah dan masyarakat sekitar sekolah. Singkatnya, pelibatan stakeholders juga bermakna upaya menguatkan stakeholders dalam rangka menguatkan program sekolah (Hopkins, 2015).

Oleh sebab itu, prinsip penting yang perlu menjadi pertimbangan kepala sekolah dalam menguatkan MSF antara lain: legitimasi, partisipasi dialog, efektivitas dan efisiensi (B.U, 2018), serta penguatan berkelanjutan SDM stakeholders (Huntjens, Lebel, \& Furze, 2015; Warner, 2007). 
Tujuannya adalah interaksi sekolah dan masyarakat berlangsung dengan berkualitas dalam rangka menghasilkan capaian tujuan secara berkualitas.

\section{SIMPULAN}

Penelitian ini menghasilkan beberapa simpulan penting, terutama dalam mewarnai khazanah ilmu pengetahuan baru yang berkaitan dengan pemilihan strategi kepemimpinan efektif berbasis kearifan lokal. Simpulan tersebut antara lain: (1) permasalahan yang dihadapi kepala SD - SMP SATAP daerah terpencil sangat terkait dengan aspekaspek aspek budaya, sosial, ekonomi, demografi, dan geografi, serta historis. Masalah yang muncul setiap aspek tersebut tidak dapat dilihat dan disikapi secara parsial melainkan harus secara komprehensif. (2) Strategi solutif kepemimpinan efektif sekolah menekankan pada aspek spiritual dengan nilai keyakinan bahwa selalu ada jalan keluar; personal yang mencakup nilai-nilai: visi jelas, spirit tinggi, andhab asor (low profile), belajar tanpa henti, tidak mudah menyerah, kreatif, sabar, santun, terbuka terhadap masukan, komitmen kerja sama, good looking); dan sosial dengan karakter: tajam melihat konteks, sadar sistem sekolah dan masyarakat, yakin keberadaannya tidak sendiri, mudah bergaul, terlibat dalam aktivitas kemasyarakatan. (3) Keterlibatan MSF perlu dilakukan secara selektif dan efektif, melalui tahapan identifikasi TKU, komunikasi intensif dengan TKU, identifikasi tokoh lain, diskusi dan berbagi peran, serta penguatan berkelanjutan.

\section{DAFTAR RUJUKAN}

Agbaria, A. K. (2015). Arab civil society and education in Israel: the Arab Pedagogical Council as a contentious performance to achieve national recognition. Race Ethnicity and Education, 18(5), 675-695. https://doi.org/ 10.1080/13613324.2012.759930

Alladi, A., \& Vadari, S. (2011). Systemic approach to project management:Astakeholders perspective for sustainability. Proceedings - 2011 Annual IEEE India Conference: Engineering Sustainable Solutions, INDICON-2011. https:// doi.org/10.1109/INDCON.2011.6139635

Anderson, A. (2016). Leadership for school improvement. Theses. https://doi. org/10.4226/66/5a9cc2feb0bb5
Arifin, I., Juharyanto, Mustiningsih, \& Taufiq, A. (2018). Islamic Crash Course as a Leadership Strategy of School Principals in Strengthening School Organizational Culture. SAGE Open, 8(3), 215824401879984. https://doi. org $/ 10.1177 / 2158244018799849$

Arnold, M. L., Newman, J. H., Gaddy, B. B., \& Dean, C. B. (2005). A Look at the Condition of Rural Education Research : Setting a Direction for Future Research. Journal of Research in Rural Education, 20(6), 1-25. https://doi. org/1551-0670

Ayene Tamrat Atsebeha. (2016). Principals' Leadership Styles and Their Effects on Teachers' Performance in the Tigray Region of Ethiopia. University of South Africa.

Banks, J. A. (1997). Educating Citizens in a Multicultural Society. Multicultural Education Series. Teachers College Press, 1234 Amsterdam Avenue, New York, NY 10027 (paperback: ISBN-0-8077-3631-7; clothbound: ISBN-0-8077-3632-5).

Barnett, K., \& McCormick, J. (2004). Leadership and Individual Principal-Teacher Relationships in Schools. Educational Administration Quarterly, 40(3), 406-434. https://doi. org/10.1177/0013161X03261742

Beare, H., Caldwell, B. J., Millikan, R. H., Caldwell, B. J., \& Millikan, R. H. (2018). Creating an Excellent School: Some New Management Techniques. Routledge.

Belfield, C. R., \& Levin, H. M. (2015). Privatizing Educational Choice: Consequences for Parents, Schools, and Public Policy. Routledge.

Bowe, R., Ball, S. J., Gold, A., Ball, S. J., \& Gold, A. (2017). Reforming Education and Changing Schools: Case studies in policy sociology. Routledge.

B.U, D. (2018). Pengantar Tata Kelola Internet. Kementerian Komunikasi dan Informatika Republik Indonesia.

Darmastuti, R., Bajari, A., Martodirdjo, H. S., \& Maryani, E. (2016). Gethok Tular, Pola Komunikasi Gerakan Sosial Berbasis Kearifan Lokal Masyarakat Samin di Sukolilo. Jurnal ASPIKOM, 3(1), 104-118. https://doi. org/10.24329/aspikom.v3i1.103

Day, C., Gu, Q., \& Sammons, P. (2016). The Impact of Leadership on Student Outcomes: How Successful School Leaders Use 
Transformational and Instructional Strategies to Make a Difference. Educational Administration Quarterly, 52(2), 221-258. https://doi. org/10.1177/0013161X15616863

Disterheft, A., Caeiro, S., Azeiteiro, U. M., \& Filho, W. L. (2015). Sustainable universities - a study of critical success factors for participatory approaches. Journal of Cleaner Production, 106, 11-21. https://doi.org/10.1016/j. jclepro.2014.01.030

Epstein, J. L. (2018). School, Family, and Community Partnerships: Preparing Educators and Improving Schools. Routledge.

Faegerlind, I., \& Saha, L. J. (2016). Education and National Development: A Comparative Perspective. Elsevier.

Findlay, R. A. (2003). Interventions to reduce social isolation amongst older people: Where is the evidence? Ageing and Society, 23(5), 647-658. https://doi.org/10.1017/S0144686X03001296

Fleischmann, B., Meyr, H., \& Wagner, M. (2015). Supply Chain Management and Advanced Planning. Concepts, Models, Software, and Case Studies. Supply Chain Management and Advanced Planning. Concepts, Models, Software, and Case Studies. https://doi. org/10.1007/978-3-540-74512-9

Gibson, A. (2014). Principals' and teachers' views of spirituality in principal leadership in three primary schools. Educational Management Administration \& Leadership, 42(4), 520-535. https://doi.org/10.1177/1741143213502195

Goddard, R., Goddard, Y., Sook Kim, E., \& Miller, R. (2015). A Theoretical and Empirical Analysis of the Roles of Instructional Leadership, Teacher Collaboration, and Collective Efficacy Beliefs in Support of Student Learning. American Journal of Education, 121(4), 501-530. https:// doi.org/10.1086/681925

Gurr, D., \& Gurr, D. (2015). A Model of Successful School Leadership from the International Successful School Principalship Project. Societies, 5(1), 136-150. https://doi.org/10.3390/ soc5010136

Hadi, N. (2010). Studi Eksplorasi Praktik Corporate Social Responsibility Serta Motif Yang Terkandung Didalamnya (Kasus Perusahaan Go Publik Dibursa Efek Indonesia). Akses: Jurnal Ekonomi Dan Bisnis, 5(9).

Hefni, M. (2007). Buppa'-Bhabhu-GhuruRato (Studi Konstruktivisme-Strukturalis tentang Hierarkhi Kepatuhan dalam Budaya Masyarakat Madura). Karsa, 11(1).

Hendrickson, W. A., \& Lattman, E. E. (1970). Representation of phase probability distributions for simplified combination of independent phase information. Acta Crystallographica Section B, 26(2), 136-143. https://doi.org/10.1107/S0567740870002078

Hopkins, D. (2015). Improving the Quality of Education for All: A Handbook of Staff Development Activities. Routledge.

Hung, D., Lim, K. Y. T., \& Lee, S.-S. (2014). Adaptivity as a Transformative Disposition for Learning in the 21st Century. https:/doi. org/10.1007/978-981-4560-17-7

Hyson, P. (2013). The spirited leader: the potential of spiritual intelligence to improve leadership. International Journal of Leadership in Public Services, 9(3/4), 109-115. https://doi. org/10.1108/IJLPS-10-2013-0028

I Made Artha Wibawa, Eka Afnan Troena, Armanu, NoermijatiLumpkin, A. (2014). The Role of Organizational Culture on Spiritual Leadership, Human Capital, and Employee Loyalty. European Journal of Business and Managemen, 6(21), 196-205. https://doi.org/1 $0.1080 / 00131725.2013 .878420$

Istiningsih, D. S. (2013). Studi Deskriptif Upaya Guru Pkn Dalam Menanamkan Sikap Nasionalisme Pada Siswa Smp Negeri Satu Atap Merjosari Kota Malang (other). University of Muhammadiyah Malang.

Jabuya, M. A., Owuor, F. O., \& Onsarigo, C. (2014). An Evaluation On Determinants Of Parental Participation In Implementation Of Academic Projects In Kenya . A Case Of Public Secondary Schools Kisumu County ., 3(2), 138-150.

Juharyanto. (2017). Kepemimpinan unggul Kepala Sekolah Dasar Daerah Terpencil (Studi Multisitus pada Sekolah Dasar di Kabupaten Bondowoso). Jurnal Sekolah Dasar, 1(Tahun 26), 89-100.

Kemendikbud Perkuat Sekolah "Satu Atap," TheTanjungpuraTimes $\S$ (2016).

King, F. J., Goodson, L., Rohani, F., Level, D. K., Plan, Q. E., Oliver, S., ... Order, H. (2015). Improving students' higher-order thinking competencies, including critical evaluation, creative thinking, and reflection on their own thinking. Research in Science Education, 3(2), 1-41. https://doi. org/10.1007/s11165-006-9029-2 
Krasnoff, B. (2015). Leadership Qualities of Effective Principals, 10.

Kurniawan, D. (2015). Pengaruh Brand Trust Dan Customer Satisfaction Terhadap Brand Loyalty: Studi Pada Pengguna Iphone Di Fakultas Ekonomi Universitas Atma Jaya Yogyakarta Angkatan 2011-2014 (S1). Uajy. Retrieved from http://e-journal.uajy.ac.id/8251/

Matthijs, M., \& Blyth, M. (2015). The Future of the Euro. Oxford University Press.

Mcculla, N., \& Degenhardt, L. (2016). Journeys to schoolleadership : How action learning identified what participants valued in a year-long Australian leadership development program centered on principles of good practice, 44(4), 558-577. https://doi.org/10.1177/1741143214558574

Pamela Munn. (2018). Parents and Schools (1993)| Customers, Managers or Partners?

Pan, H.-L. W., Nyeu, F.-Y., \& Chen, J. S. (2015). Principal instructional leadership in Taiwan: lessons from two decades of research. Journal of Educational Administration, 53(4, SI), 492511. https://doi.org/10.1108/JEA-01-2014-0006

Piter Joko Nugroho. (2014). Faktor-faktor Yang Mempengaruhi Profesionalisme Guru SD Daerah Terpencil Kabupaten Gunung Mas Provinsi Kalimantan Tengah. Jurnal Pendidikan Lentera Dinas Pendidikan Kabupaten Bondowoso, 1(1), 19-36.

Roberts, B., \& Buch, N. D. (2016). No regrets in the evening of life: Access, equity and exclusivity at Junction Park State School in the early twentieth century. History of Education Review, 45(1), 69-87. https://doi.org/10.1108/ HER-03-2014-0023

Schneider, M., \& Buckley, J. (2002). What Do Parents Want From Schools? Evidence From the Internet. Educational Evaluation and Policy Analysis, 24(2), 133-144. https://doi. org/10.3102/01623737024002133

Schrag, F. (2016). Thinking in School and Society. Routledge.

Sigrı'ður Margre 't Sigurðardo ' ttir, R. 'nar S. 'rsson. (2016). The Fusion of School Improvement and Leadership Capacity in an Elementary School. Educational Management Administration \& Leadership, 44(4), 599-616. https://doi.org/10.1177/1741143214559230

Suryono, J. (2013). Model Media Iklan Potensial Yang Tepat Sasaran Produk Unggulan UKM.
Profetik, 6(2).

Tchibozo, G. (2013). Cultural and Social Diversity and the Transition from Education to Work. (Guy Tchibozo, Ed.) (Vol. 17). https://doi. org/10.1007/978-94-007-5107-1

Tilaar, H. A. R. (1998). Beberapa agenda reformasi pendidikan nasional dalam perspektif abad 21. IndonesiaTera.

Touraine, A. (2017). The Academic System in American Society. Routledge.

Trianton, T. (2015). Dalam Khazanah Budaya Cablaka. Ibda', Jurnal Kebudayaan Islam, 11(2), 211-226.

Tveit, A. D., Cameron, D. L., \& Kovač, V. B. (2014). "Two Schools under one Roof" in Bosnia and Herzegovina: Exploring the challenges of group identity and deliberative values among Bosniak and Croat students. International Journal of Educational Research, 66, 103-112. https://doi.org/10.1016/j.ijer.2014.03.004

Urick, A. (2016). Examining US principal perception of multiple leadership styles used to practice shared instructional leadership. Journal of EducationalAdministration, 54(2pp.),152-172. http://dx.doi.org/10.1108/09564230910978511

Wahyono, S. B. (2011). Optimalisasi Program Desa Informasi Melalui Penguatan Kelembagaan. Jurnal Penelitian IPTEK-KOM, 13(2), 29-42.

Wijayanti, W. (2011). Implementasi Kebijakan SDSMP Satu Atap (Studi Multisitus di Kecamatan Ngablak, Pakis dan Sawangan Kabupaten Magelang). (Disertasi). DISERTASI dan TESIS Program Pascasarjana UM, O(0).

Wulandari2, N. D. (2018). Pengaruh Penggunaan Gadget Terhadap Tingkat Prestasi Sisswa SMP N Satu Atap Pakis Jawa Karawang. Jurnal Ilmu Pengetahuan Dan Teknologi Komputer.

Yuliastuti, I., Syukri, M., \& Martono, H. (2016). Principals' leadership in implementing one roof school in Kuala Mandor District [Kepemimpinan kepala sekolah dalam menyelenggarakn pendidikan sekolah satu atap di Kecamatan Kuala Mandor]. Jurnal Pendidikan Dan Pembelajaran.

Zakub, R., Widodo, S. T., \& Setiawan, B. (2018). The Relevance Between Javanese Pitutur Luhur and Islam Religiosity. IBDA': Jurnal Kajian Islam Dan Budaya, 16(1), 148-164. https://doi.org/10.24090/ibda.v16i1.1659 